\title{
Spontaneous Rupture of a Choledochal Cyst During Post Partum: A Rare Presentation
}

\author{
Ashish Gupta ${ }^{\text {a }}$, Karikal Chakaravarthi ${ }^{\text {a }}$, Lileswar Kaman ${ }^{\mathrm{a}, \mathrm{b}}$
}

\begin{abstract}
With the advent of newer radiological investigations, choledochal cysts are being diagnosed more often in present era. These cysts are commonly diagnosed in early childhood and infancy, although some go undetected to be diagnosed in adulthood. These malformations are associated with multiple complications like cholangitis, jaundice, pancreatitis, rupture or even malignancy. Here we describe a post partum female, who was diagnosed to have choledochal cyst during sixth month of pregnancy. She presented with obstructive jaundice in cholangitis and was subjected to endoscopic retrograde cholangiopancreatography (ERCP) with stenting. This female delivered normally at term. She again had jaundice with cholangitis during early post partum period. Endoscopic stenting could be performed. She had features of peritonitis after 1 week of stenting. Investigations were performed and a diagnosis of spontaneous rupture of choledochal cyst was made. She underwent laparotomy and lavage with complete excision of the choledochal cyst and Roux-en-Y hepaticojejunostomy.
\end{abstract}

Keywords: Choledochal cyst; Spontaneous rupture; Pregnancy; Post partum

\section{Introduction}

Choledochal cysts are congenitally malformed thin walled, dilated, intrahepatic or extrahepatic bile ducts [1]. These cysts offer a major challenge for diagnosis and treatment during pregnancy because of the altered physiology associated with it [2]. There has to be fine balance between the benefits as well as the risks associated with the treatment. The rupture of the cyst is common in children [3]. It is secondary to raised intracystic pressure because of distal stricture or stones [4, 5]. Multiple complications of the cysts are reported during pregnancy [6]. Spontaneous rupture of the choledochal cyst during immediate

Manuscript accepted for publication January 23, 2017

aDepartment of General Surgery, PGIMER, Chandigarh 160012, India ${ }^{b}$ Corresponding Author: Lileswar Kaman, Department of General Surgery, PGIMER, Chandigarh 160012, India. Email: drashish0403@gmail.com

doi: https://doi.org/10.14740/gr781w post partum has rarely been reported [7, 8]. Here we describe a young female who presented to us with choledochal cyst with cholangitis during pregnancy. She underwent multiple endoscopic retrograde cholangiopancreatography (ERCP) to tide over the pregnancy. But unfortunately she presented in the immediate post partum with peritonitis secondary to spontaneous rupture of the cyst. She underwent cyst excision and bilioenteric anastomosis in emergency. The rarity of this presentation in post partum poses a diagnostic dilemma in the minds of treating clinician. This complication should be kept in mind while treating a known patient of choledochal cyst who presents to the emergency with peritonitis.

\section{Case Report}

A 27-year-old primigravida presented to surgical emergency with obstructive jaundice and grade II cholangitis at 6 months of pregnancy. She was evaluated and was found to have a choledochal cyst on ultrasound and this was subsequently confirmed as type IV (Fig. 1) on magnetic resonance cholangiopancreatography (MRCP). For these complaints, she underwent ERCP and a biliary stent was placed so as to tide over the situation. She was relieved off cholangitis with this management. She was managed with intravenous antibiotics. This patient was shifted to maternity ward where she delivered vaginally at term. This female again had cholangitis 2 weeks post partum. An endobiliary stent could be placed and she was being managed conservatively but had pain abdomen, fever and vomiting 1 week after stenting. She was dehydrated on examination. Tachycardia (PR: 120/min) was present and there was generalized guarding and rigidity on abdominal examination. A contrast-enhanced CT scan was done that revealed the rupture of the suprapancreatic part of the choledochal cyst with free fluid in the abdominal cavity (Fig. 2). After optimization, this patient underwent cyst excision with Roux-en-Y hepaticojejunostomy. Intraoperative findings (Fig. 3) included $500 \mathrm{~mL}$ biliopurulent fluid with pus flakes present in abdominal cavity. Bowel loops were normal. Dense adhesions were present between duodenum, CBD, omentum, and parietal wall. There was rent of $1 \mathrm{~cm}$ in the lateral wall of the choledochal cyst. Histopathology of this excised cyst confirmed the choledochal cyst rupture without any evidence of dysplasia (Fig. 4). The patient did well in the postoperative period and was discharged on the 10th postoperative day. The liver functions and the ul- 


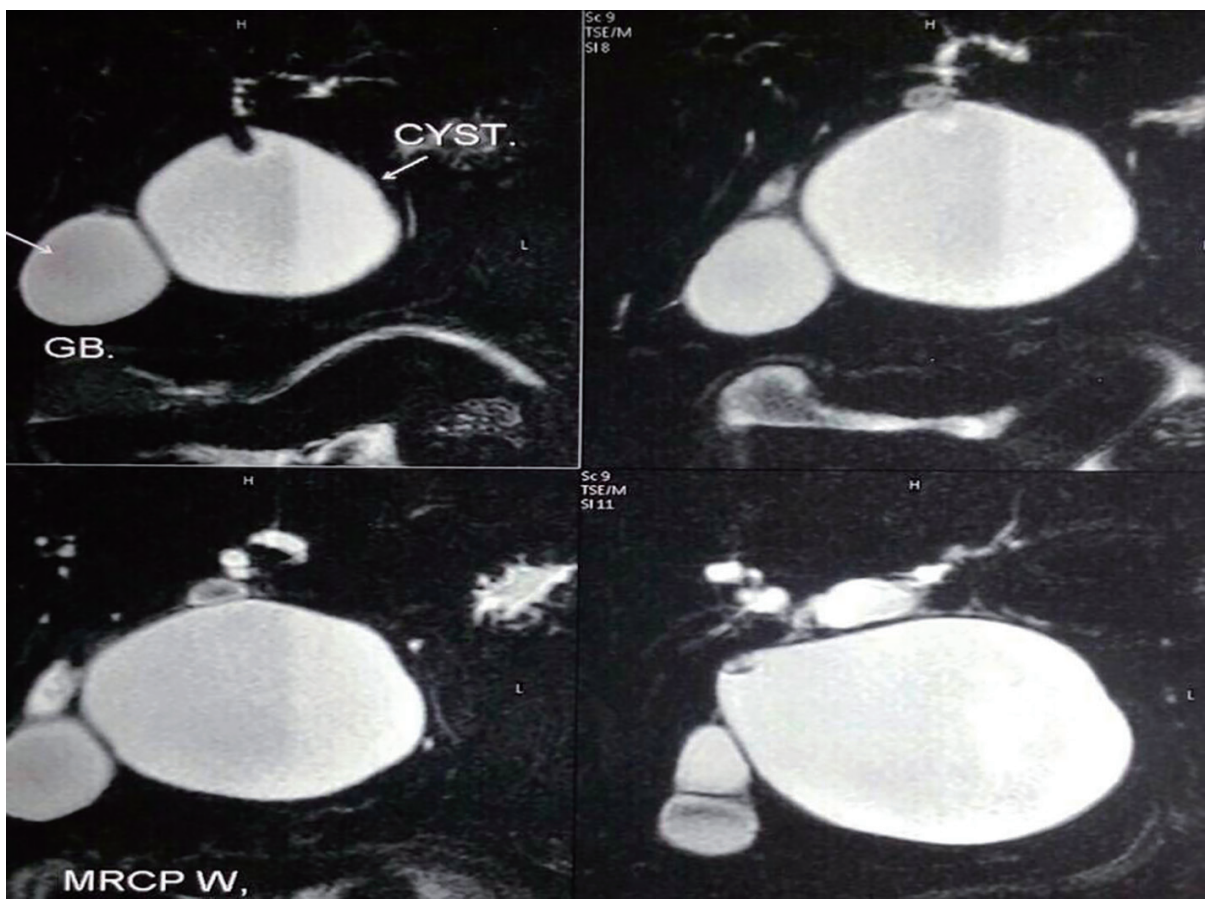

Figure 1. MRCP of the patient showing choledochal cyst.

trasound are within normal 1 year after discharge. The baby is having normal developmental milestones till date.

\section{Discussion}

With recent advances in medical science, choledochal cyst is diagnosed $25 \%$ of the times during adulthood and rarely during pregnancy $[9,10]$. It is associated with multiple complications during pregnancy like cholangitis, preterm labor, abortion and even rupture [6]. The choledochal cyst when diagnosed during pregnancy provides both therapeutic and diagnostic challenge. The cumulative risk of spontaneous choledochal cyst rupture

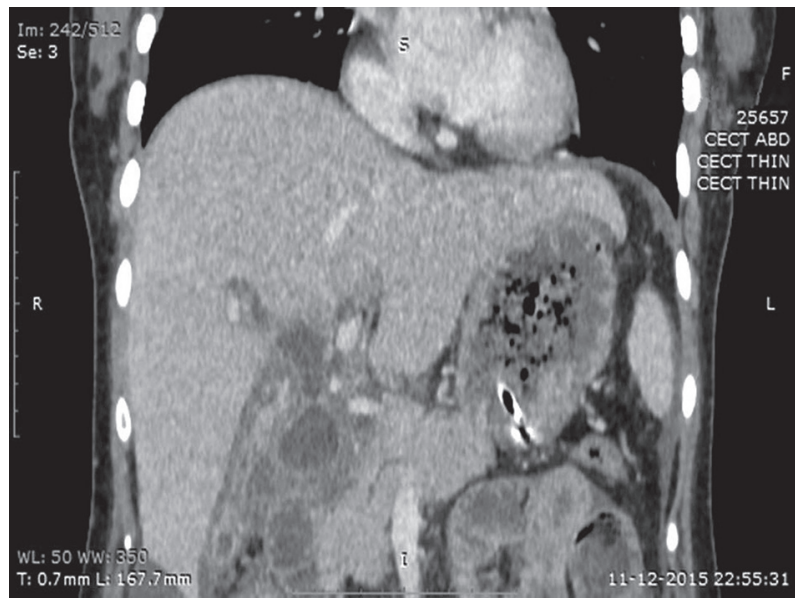

Figure 2. CECT of abdomen of the patient showing cyst rupture with free fluid. varies between $1.8 \%$ and $2.8 \%$ [11-13]. Rupture is more common during childhood and rare during post partum period of the pregnancy [3].

Various etiologies have been proposed for the spontaneous rupture of the cyst. Weakness of the dilated cyst wall with raised intracystic pressure because of stones/strictures, trauma due to multiple interventions, regurgitation of the amylase rich fluid in the bile duct and association of the anomalous pancreatobiliary junction are the commonly reported in literature [14-

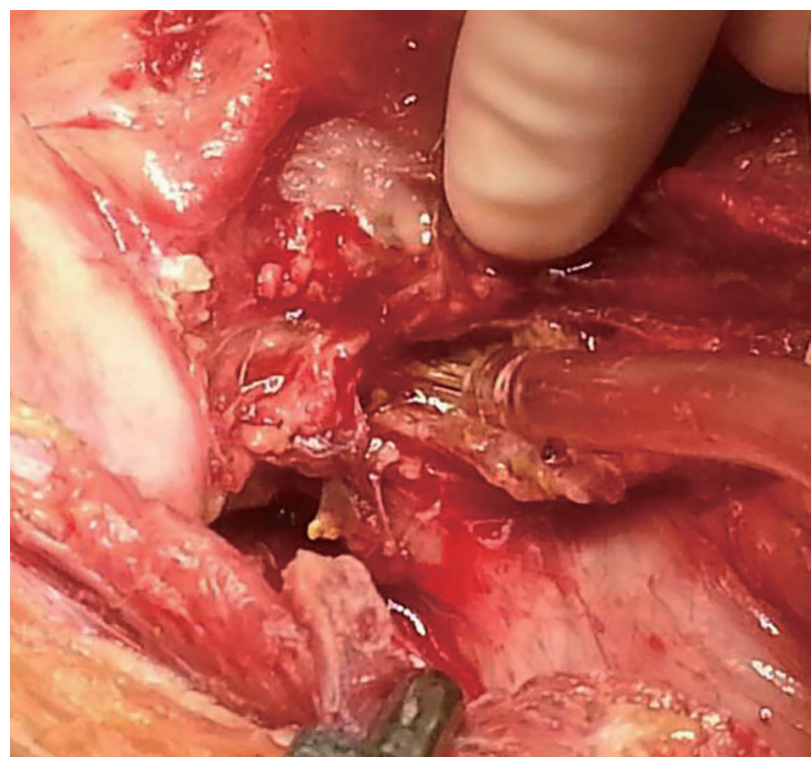

Figure 3. Intraoperative photograph of the cyst with rent on the lateral wall. 


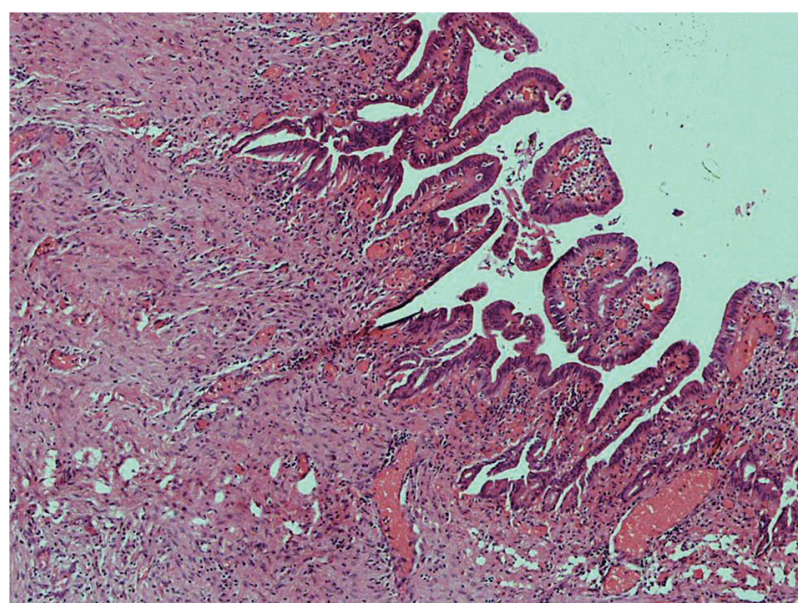

Figure 4. Photomicrograph of the cyst wall.

18]. Multiple ERCP and stent placement secondary to cholangitis causing the CBD weakness is the most probable cause of rupture in the present case.

This patient presented to us in cholangitis mandating biliary drainage. Endobiliary drainage is the preferred mode of the drainage. ERCP is associated with increased risk of radiation exposure and subsequent malformations in the fetus. Many studies have proved the efficacy of ERCP during pregnancy particularly when the radiation dose to the fetus is calculated [19]. Use of lead shield to block the radiation has also proven useful. ERCP when indicated should be done with utmost care and in controlled conditions to prevent fetal damage.

The surgery for the choledochal cyst should be done after delivery. However, pregnancy along with increased pressure during childbirth puts these patients at risk for cyst rupture and fetal loss [6]. We were successful in this strategy to a greater extent. We tided over the complications of the cyst with minimally invasive techniques but repeated interventions for the same might have triggered the rupture.

There is no consensus on the management of the ruptured choledochal cyst due to the rarity of the condition. There are multiple factors guiding the treatment. Friability of the cyst wall, hemodynamic instability, inflammation and edematous bowel mandate the drainage of the CBD either with a T-tube or percutaneous transhepatic drain [2,3]. This is followed by a definitive surgery once the acute crisis is controlled. Alternatively, single stage operation of cyst excision with bilioenteric drainage can be performed provided the intraoperative conditions are favorable [20]. This patient had normal bowel with minimal inflammation of the bile duct so single stage operation was contemplated.

\section{Conclusion}

Choledochal cyst provides a therapeutic as well as diagnostic challenge during pregnancy. Cyst rupture should be kept as a differential diagnosis whenever a known patient harboring choledochal cyst presents with peritonitis. Pregnancy with choledochal cyst rupture puts the maternal as well as fetal life at risk. ERCP is a safe modality to control biliary complications of the choledochal cysts. Surgery for the cyst should be done after completion of the pregnancy.

\section{Conflicts of Interest}

None.

\section{Funding}

None.

\section{Author Contributions}

AG, KC and LK were involved in writing, editing and approval of the manuscript. LK is the article guarantor.

\section{References}

1. Altman RP. Choledochal cyst. Semin Pediatr Surg. 1992;1(2):130-133.

2. Pal S, Simon EG, Koshy AK, Ramakrishna BS, Raju RS, Vyas FL, Joseph P, et al. Spontaneous choledochal cyst rupture in pregnancy with concomitant chronic pancreatitis. Indian J Gastroenterol. 2013;32(2):127-129.

3. Ahmed I, Sharma A, Gupta A, Chandra N, Rawat J, Singh S. Management of rupture of choledochal cyst. Indian J Gastroenterol. 2011;30(2):94-96.

4. Hart DE. Spontaneous perforation of the common bile duct. Ann Surg. 1951;133(2):280-282.

5. Spira IA. Spontaneous rupture of the common bile duct. Ann Surg. 1976;183(4):433-435.

6. Furuhashi S, Takamori H, Nakahara O, Ikuta Y, Tanaka $\mathrm{H}$, Horino K, Baba H. Choledochal cyst during pregnancy: case report and literature review of treatment. Clin J Gastroenterol. 2013;6(4):326-328.

7. Oncu M, Alhan E, Calik A. Rupture of a choledochal cyst during postpartum period. Z Gastroenterol. 1990;28(8):396-398.

8. Kitahama A, Harkness SO, Moynihan PO, Webb WR. A large choledochal cyst with impending rupture post partum. Br J Surg. 1984;71(2):156.

9. Hewitt PM, Krige JE, Bornman PC, Terblanche J. Choledochal cyst in pregnancy: a therapeutic dilemma. J Am Coll Surg. 1995;181(3):237-240.

10. Nassar AH, Chakhtoura N, Martin D, Parra-Davila E, Sleeman D. Choledochal cysts diagnosed in pregnancy: a case report and review of treatment options. J Matern Fetal Med. 2001;10(5):363-365.

11. Tan KC, Howard ER. Choledochal cyst: a 14-year surgical experience with 36 patients. Br J Surg. 1988;75(9):892895.

12. Yamaguchi M. Congenital choledochal cyst. Analysis of 1,433 patients in the Japanese literature. Am J Surg. 
1980;140(5):653-657.

13. Kim SH. Choledochal cyst: survey by the surgical section of the American Academy of Pediatrics. J Pediatr Surg. 1981;16(3):402-407.

14. Donahoe PK, Hendren WH. Bile duct perforation in a newborn with stenosis of the ampulla of Vater. J Pediatr Surg. 1976;11(5):823-825.

15. Blocker TJ, Williams JE. Traumatic rupture of a congenital cyst of choledochus. Arch Surg. 1983;34:690-695.

16. Diamond T, Panesar KJ. Biliary peritonitis due to choledochal cyst presenting in late pregnancy. Ulster Med J. 1986;55(2):190-192.

17. Ohkawa H, Takahashi H, Maie M. A malformation of the pancreatico-biliary system as a cause of perforation of the biliary tract in childhood. J Pediatr Surg. 1977;12(4):541546.

18. Treem WR, Hyams JS, McGowan GS, Sziklas J. Spontaneous rupture of a choledochal cyst: clues to diagnosis and etiology. J Pediatr Gastroenterol Nutr. 1991;13(3):301306.

19. Lee JJ, Lee SK, Kim SH, Kim GH, Park do H, Lee S, Seo D, et al. Efficacy and Safety of Pancreatobiliary Endoscopic Procedures during Pregnancy. Gut Liver. 2015;9(5):672-678.

20. Moss RL, Musemeche CA. Successful management of ruptured choledochal cyst by primary cyst excision and biliary reconstruction. J Pediatr Surg. 1997;32(10):14901491. 